\title{
DIGITAL BADGES IN HIGHER EDUCATION: A THREE-PHASE STUDY ON THE IMPLEMENTATION OF DIGITAL BADGES IN AN ONLINE UNDERGRADUTE PROGRAM
}

\author{
Maria Elena Corbeil, The University of Texas Rio Grande Valley, mariaelena.corbeil@utrgv.edu \\ Joseph Rene Corbeil, The University of Texas RioGrandeValley, rene.corbeil@utrgv.edu \\ Ignacio E. Rodriguez, The University of Texas Rio Grande Valley, ignacio.rodriguez@utrgv.edu
}

\begin{abstract}
Digital badges originated in the gaming world as incentives built into video games to acknowledge gamers' achievements. They have only recently been identified by course designers and instructors in formal and corporate education as a way to support competency-based learning and acknowledge achievement of specialized knowledge and skills. The faculty of an undergraduate Educational Technology specialization are implementing badges in 6 fully online courses through a three-phase study. Students who excel in specific skills through their coursework would become eligible to earn digital badges in the specific EdTech areas. The purpose of the proposed study is to determine if digital badges motivate learners to excel in their academic work and if the earned badges provide graduates a competitive advantage when applying for a job. This article will present the justification for the use of digital badges, their educational significance, as well as the purpose, design, and methodology of the three-phase study.
\end{abstract}

Keywords: Digital Badges, E-Learning, Educational Technology, Corporate Training, Online

\section{INTRODUCTION}

Although digital badges have been in use in video games and informal educational settings for over ten years, they have only recently been adopted in higher education and the workplace to support competency-based learning and acknowledge achievement of specialized knowledge and skills. The Educational Technology program at The University of Texas Rio Grande Valley is implementing a digital badges initiative for its undergraduate specialization through a three-phase research study. Students who excel in specific skills through their academic coursework will become eligible to earn a digital badge in each of the following areas:

- Instructional Design

- Web-Based Instruction

- Multimedia Development
- Digital Collaboration

- Social Media Networking

- EdTech Leadership

Earned badges can be added to students' e-portfolios, resumes, and professional social media networking accounts. The following illustration represents the six digital badges students will be eligible to earn.

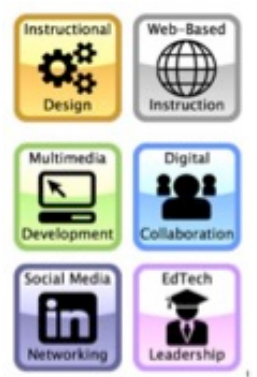

Figure 1. The Six Educational Technology Badges

The purpose of the proposed study is twofold to determine: (1) if digital badges motivate learners to excel in their 
academic work, and (2) if the earned badges provide graduates a competitive advantage when applying for a job. The study will be completed in three phases. In Phase I, current undergraduate Educational Technology students will be surveyed to assess their awareness of and perceptions regarding the use of digital badges as motivators to learn and as assets in competitive work related matters. In Phase II, digital badges will be integrated to all six of the online undergraduate Educational Technology specialization courses and student performance will be evaluated. In Phase III, the perceived impact of digital badges on program graduates' qualifications for employment, as well as graduates' perceptions regarding employers' awareness and appreciation of digital badges will be assessed. The justification for the use of digital badges and their educational significance, as well as the purpose, design, and methodology of the three-phase research study will be presented in this paper.

\section{BACKGROUND/JUSTIFICATION}

Dictionary.com [3] defines a badge as, "a special or distinctive mark, token, or device worn as a sign of allegiance, membership, authority, achievement" (para. 1). Badges have been used for hundreds of years to represent authority and distinction in knowledge and skills. In the United States, it is easy to recall earning a Girl or Boy Scout badge for demonstrating mastery of a specific skill, or seeing badges on military and law enforcement uniforms that represent rank and special commendations. Today, with the proliferation of online learning resources and professional development options, badges have become digital and have taken on completely new applications, opening up a whole new world of opportunities for professionals.

Digital badges got their start in 2005, when Microsoft introduced a game system that provided awards for specific milestones. The author of Badges for Learning: An Abridged Recent History [4] noted that Microsoft's Xbox 360 Gamerscore system "is considered to be the original implementation of an achievement system." Over the next couple of years, other game companies, such as Sony and Valve developed similar strategies for awarding achievements with trophies [10]. Today, badges are an integral part of video games and have extended beyond the realm of gaming into business and education.

In business, especially with the recent explosion of just-in-time learning opportunities provided by the web in the form of online professional development, a challenge arose regarding how professionals could document and demonstrate the credentials they earned online. Companies offering online professional development opportunities turned to digital badges. In education, the idea of using digital badges was introduced by the American Educational Research Association (AERA) president Eva Baker at their annual convention in 2007 [4]. In her presentation, Dr. Baker strongly supported the implementation of digital badges to alleviate the assessment challenges plaguing the school system in the United States. Baker [5] noted "the path of Qualifications shifts attention from schoolwork to usable and compelling skills, from school life to real life" (para. 2).

It was not until 2011, when a turning point in the use of digital badges in education came with the publication of $A n$ Open Badge System Framework [7]. According to the report, digital badges "have been successfully used to set goals, motivate behaviors, represent achievements and communicate success in many contexts...badges can have a significant impact, and can be used to motivate learning, signify community and signal achievement" (What is a Badge, para. 1). According to Reconnect Learning [8], "[d]igital badges can hold much more information about what a learner has accomplished and what competencies they've developed than a letter grade can convey" (Badges for Learning, p. 1). Carey [2] added that, "[w]hile they may appear to be just images, digital badges are actually portals that lead to large amounts of information about what their bearers know and can do" (para. 3). He added that digital badges have the potential to actually improve education using game-based techniques for assessment, rewards, and incentives. The evidence, he continues, is in the fact that "[b]adges are gaining currency at the same time that a growing number of elite universities have begun offering free or low-cost, noncredit courses to anyone with access to the Internet and a desire to learn" [2]. The free Massive Open Online Courses (MOOCs), offered by companies and increasingly more higher education institutions, have already had thousands of students registered in their courses. Some of these courses use badges to provide learners with a way to demonstrate the knowledge and skills they have acquired. Carey [2] observed, "creators of badge programs may be mounting the first serious competition to traditional degrees since college-going became the norm" (para. 4).

The Educational Technology faculty at The University of Texas Rio Grande Valley recognize the value of digital badges and have designed a three phase research study to integrate them into the fully online undergraduate 
specialization. The proposed study will be conducted at The University of Texas Rio Grande Valley by a team of faculty in the Education Technology program. The fully online Educational Technology specialization consists of six undergraduate courses and is part of the Bachelors of Applied Technology, Bachelors of Applied Arts and Sciences, and Bachelors of Multidisciplinary Studies. In addition, some students take the courses as electives for other bachelors' degrees. The EdTech specialization is also part of the Finish@UT degree completion program through which students from all of the University of Texas system universities can take one or more courses. Prior to starting this study, Human Subjects approval was obtained from the University Institutional Review Board (IRB). The following section describes each phase of the research study.

\section{PHASE I: UNDERGRADUATE EDUCATIONAL TECHNOLOGY STUDENTS SURVEY}

During the first phase of the three-part research study, students will be surveyed to determine their perceptions regarding the use of digital badges on student motivation towards academic achievement and competitive advantage in current/future employment.

\section{Participants}

Participants will be drawn from the entire population of students enrolled in the online undergraduate Educational Technology specialization. The majority of the students are non-traditional working adults who work full or part time across a wide array of disciplines (ex.: healthcare, education, business, military, computer science, etc.). Currently, there are approximately 120 students enrolled in six courses. All students will be invited to participate in the survey.

\section{Research Questions/Hypothesis}

- Research Question 1: To what extent do undergraduate Educational Technology students value digital badges as motivators in their academic coursework?

- Research Hypothesis 1: Undergraduate Educational Technology students value digital badges as motivators to excel in their academic coursework.

- Research Question 2: To what extent do undergraduate Educational Technology students believe digital badges can give them a competitive advantage in current or future employment?

- Research Hypothesis 2: Undergraduate Educational Technology students believe digital badges can give them a competitive advantage in current or future employment.

\section{Data Collection}

During the Spring and Summer 2015 semesters, an announcement with an invitation to participate in the online survey will be posted in each of the courses. The announcement consists of a welcome message; a short video describing how digital badges can recognize formal and informal learning and special accomplishments; and a link to the informed consent form. To protect the rights of the participants, an explanation of the purpose of the research, the expected length of time of the participants' involvement, and a description of the procedures to be followed will be provided. Participants will also be informed that only group data will be reported and their identities will remain anonymous.

\section{Instrumentation}

The online survey consists of a welcome message and a link to the informed consent form. Only students who agree to participate will be directed to a web page with a short video that describes how digital badges can recognize formal and informal learning and special accomplishments, as well as the link to the Phase I survey questions. The survey consists of 3 sections (see survey below). Section I collects participant demographic data. Section II utilizes a seven-category forced-choice rating scale, ranging from Strongly Agree to Strongly Disagree. In this section, participants are asked to indicate to what extent they agree with each of the five statements by clicking the corresponding radio button for their response. Section III includes 2 open-ended questions. 
INSTRUCTIONS: This survey was designed to gather data on undergraduate students' perceptions toward the use of digital badges to recognize the attainment of specific course-related skills and knowledge.

I. DEMOGRAPHIC INFORMATION. Please tell us a little about yourself.

Gender:

Female

Male
Age:

$\begin{array}{ll}18-20 & 46-50 \\ 21-25 & 51-55 \\ 26-30 & 56-60 \\ 31-35 & 61-65 \\ 36-40 & 66-70 \\ 41-45 & 71-\text { Above }\end{array}$

Employment Status:

Part-time

Full-time

Not employed

\section{What field do you work in? (Check all that apply.)}

Not employed

Agriculture and Mining

Construction

Trade, Transportation, \& Utilities

Manufacturing

Information

Finance and Insurance

Real State and Rental and Leasing

Professional, Business, \& Technical Services

Education

Health

Leisure and Hospitality

Government

Military Services

\section{Ethnicity:}

Hispanic

White, non-Hispanic

Asian

African American

Native American

Other (please specify)

What kind of job do you do? Please describe:

Have you ever earned a digital badge as part of personal or professional development or independent study? Yes

No

If yes, please elaborate:

II. SURVEY QUESTIONS. The survey questions will utilize a seven-category forced-choice rating scale, ranging from Strongly Agree, to Strongly Disagree. There are no right or wrong answers to these statements. Please indicate how much you agree with each statement as it describes you by clicking the corresponding radio button for your response. After reading each statement, please indicate the degree to which you feel that each statement is true for you.

\begin{tabular}{|c|c|c|c|c|c|}
\hline $\begin{array}{l}\text { Strongly } \\
\text { Agree }\end{array}$ & $\begin{array}{l}\text { Somewhat } \\
\text { Agree }\end{array}$ & Agree & Neutral & Disagree & $\begin{array}{l}\text { Somewhat } \\
\text { Disagree }\end{array}$ \\
\hline
\end{tabular}

1. I would like the opportunity to earn a digital badge to recognize my mastery of course-related skills and knowledge.

2. The opportunity to earn a digital badge would motivate me to work harder in my Educational Technology courses.

3. Digital badges could give me a competitive advantage in my current job or when applying for a new job.

4. Digital badges can emphasize the attainment of skills that may otherwise be hidden from prospective employers.

5. If I was an employer, I would consider digital badges included on an applicant's resume.

\section{OPEN ENDED QUESTIONS}

1. What do you think of the use of digital badges to recognize mastery of specific course-related skills and knowledge?

2. Do you think employers would consider digital badges in employment decisions? 


\section{Data Analysis}

Given that the research team designed the items in this survey, the Phase I survey will be pilot tested prior to implementation. Cronbach's alpha for internal consistency will be computed to see if there are items in the questionnaire that would improve the reliability if deleted. Descriptive statistics will also be calculated in determining means, mode, range, variance, standard deviation, frequencies, and percentages.

\section{PHASE II: INTEGRATE DIGITAL BADGES INTO THE UNDERGRADUATE EDUCATIONAL TECHNOLOGY ONLINE COURSES}

In the second phase of this study, six existing undergraduate Educational Technology courses will be modified to include the option for students to earn a digital badge for mastering course-specific skills. Undergraduate faculty teaching the courses will be instructed to modify their syllabus by adding a statement regarding the description and criteria for earning a badge. Syllabi statements and badge images will be provided by the researchers to the faculty according to the different course topics.

Mozilla's Open Badges initiative was selected for the digital badges project because it provides an open standard infrastructure that is secure, yet easy for organizations to create, issue, and verify digital badges. According to the Mozilla Open Badges Wiki [6], "[o]pen Badges are information-rich. Each badge has important metadata, which is hard-coded into the badge image file itself that links back to the issuer, criteria and verifying evidence" (Digital Badges vs. Open Badges, para. 2). The hard-coded metadata helps to safeguard the legitimacy of the badges program by preventing individuals from claiming unearned badges as their own. In each course, students will be guided in the setup of their own Mozilla Backpack. This backpack will enable students to manage and share their earned badges with others.

In addition to modifying courses' syllabi, the Educational Technology e-portfolio the students develop throughout the six courses will also be adapted to include a page for displaying earned badges. At the end of each semester, students will add earned badges to their e-portfolios and update their LinkedIn profiles. In the Practicum course (EDTC 3332), students will develop a professional resume that incorporates their earned badges into a Specialized Knowledge and Skills section. Upon graduation, students may submit their resume to current and prospective employers.

\section{Research Questions/Hypothesis}

- Research Question 3: What is the effect of the implementation of digital badges on the academic achievement of undergraduate Educational Technology students as measured by end-of-course grades?

- Research Hypothesis 3: There is a statistically significant difference in the academic achievement of the students enrolled in the online undergraduate Educational Technology specialization courses during the implementation of the digital badges pilot study and the academic achievement of the students enrolled in the online undergraduate Educational Technology specialization prior to the implementation of the digital badges pilot study.

\section{Data Collection}

In order to determine the impact of digital badges on academic achievement, end-of-course grades will be gathered from all of the students who completed courses one year prior to, and one year after the integration of digital badges into the Educational Technology courses. At the end of each semester, the Educational Technology faculty who teach each course, will record final course grades into the learning management system gradebook; export the grades to an Excel file; and submit the file to the coordinator for the undergraduate Educational Technology specialization program. The researchers will review the grades and issue digital badges to students earning an end-of-course grade of $\mathrm{A}+(98-100)$. 


\section{Data Analysis}

A comparison between end-of-course grades of students in the first year of the implementation of digital badges and the end-of-course grades of students who completed the same six undergraduate Educational Technology specialization courses in the previous academic year will be performed by using a two independent samples t-test to detect any statistically significant differences. Descriptive statistics will also be calculated in determining means, mode, range, variance, standard deviation, frequencies, and percentages.

\section{PHASE III: UNDERGRADUATE EDUCATIONAL TECHNOLOGY SPECIALIZATION GRADUATE SURVEY}

In the third and final phase, the researchers will survey program graduates to determine if the digital badges incorporated into their resumes and professional networking accounts gave them a competitive edge when applying for a job or in their current jobs. The online survey will also inquire into graduates' perceptions regarding employers' awareness and appreciation of digital badges.

Badge earners' names and email addresses will be maintained through Achievery, a digital credential and badge system that integrates with Mozilla's Open Badges system. According to the Achievery web site [1]:

Achievery provides a customizable and secure digital credential and badge platform, compatible with the Open Standards, and easily integrated with your existing learning platform and curricula. Achievery supports the development of systems exclusively for competency-based schools, colleges, and innovative learning models that are looking for a better way to recognize, verify, and connect the real skills of their students (para. 1).

An added benefit of the Achievery platform is the ability to track real-time data on students' learning gains.

\section{Participants}

Since EDTC 3332: Instructional Technology Practicum is the final course in the undergraduate Educational Technology specialization, within six months of graduation, completers of this course who earned one or more badges will receive an email invitation to participate in a follow-up online survey. Only graduates who agree to participate will be directed to the survey.

\section{Research Questions/Hypothesis}

- Research Question 4: To what extent do undergraduate Educational Technology graduates believe digital badges gave them a competitive advantage in past and/or current employment?

- Research Hypothesis 4: Undergraduate Educational Technology graduates believe digital badges gave them a competitive advantage in past and/or current employment.

- Research Question 5: To what extent do undergraduate Educational Technology graduates believe their employers are familiar with and recognize the value of digital badges for employment decisions?

- Research Hypothesis 5.1: Undergraduate Educational Technology graduates believe their employers are familiar with digital badges.

- Research Hypothesis 5.2: Undergraduate Educational Technology graduates believe their employers recognize the value of digital badges for employment decisions. 


\section{Data Collection}

Only students who complete the practicum course and earn one or more digital badges will be invited to participate in a follow up survey via an email that includes a description of the study and a link to the electronic consent form. To protect the rights of the participants, an explanation of the purpose of the research, the expected length of time of the participants' involvement, and a description of the procedures to be followed will be fully explained. Participants will also be informed that only group data will be reported and their identities will remain anonymous. After agreeing to participate, graduates will be directed to the survey.

\section{Data Analysis}

Given that the items in this survey were designed by the research team, the survey will be pilot tested. Cronbach's alpha for internal consistency will be computed to see if there are items in the questionnaire that would improve the reliability if deleted. Descriptive statistics will also be calculated to determine means, mode, range, variance, standard deviation, frequencies, and percentages.

\section{Instrumentation}

The online survey for Phase III will consist of a welcome message and a link to the consent form. Graduates who agree to participate will be given access to the survey questions.

The survey is composed of 3 sections (see survey below). Section I collects participant demographic data. Section II utilizes a seven-category forced-choice rating scale, ranging from Strongly Agree to Strongly Disagree. In this section, participants will be asked to indicate to what extent they concur with each of the statements below by clicking the corresponding radio button for their response. Section III includes 2 open-ended questions.

INSTRUCTIONS: The survey was designed to gather data on the perceptions of graduates from the undergraduate specialization in Educational Technology toward the use of digital badges to recognize the attainment of specific course-related skills and knowledge.

I. DEMOGRAPHIC INFORMATION. Please tell us a little about yourself.

\section{Gender:}

Female

Male
Age:

$\begin{array}{ll}18-20 & 46-50 \\ 21-25 & 51-55 \\ 26-30 & 56-60 \\ 31-35 & 61-65 \\ 36-40 & 66-70 \\ 41-45 & 71-\text { Above }\end{array}$

\section{What field do you work in? (Check all that apply.)}

Not employed

Agriculture and Mining

Construction

Trade, Transportation, and Utilities

Manufacturing

Information

Finance and Insurance
Employment Status:

$\begin{array}{ll}\text { Part-time } & \text { Hispanic } \\ \text { Full-time } & \text { White, non-Hispanic } \\ \text { Not employed } & \text { Asian } \\ & \text { African American } \\ & \text { Native American } \\ & \text { Other (please specify) }\end{array}$

\section{Ethnicity: \\ African American \\ Other (please specify)}

Real State and Rental and Leasing

Professional, Business, and Technical Services

Education

Health

Leisure and Hospitality

Government

Military Services

Other:

What kind of job do you do? Please describe:

Since graduating from the program, have you earned additional digital badge(s) as part of personal or professional development?

Yes If yes, please elaborate:

No

II. SURVEY QUESTIONS. The survey questions will utilize a seven-category forced-choice rating scale, ranging from Strongly Agree, to Strongly Disagree. There are no right or wrong answers to these statements. Please indicate how much you agree with each statement as it describes you by clicking the corresponding radio button for your response. After reading each statement, please indicate the degree to which you feel that each statement is true for you. 


\section{Section A: (Everyone Answer) \\ 1. The opportunity to earn a digital badge motivated me to work harder in my classes. \\ 2. The digital badges on my resume gave me a competitive advantage in my current job or when applying for a new job. \\ 3. The digital badges on my resume emphasized the attainment of skills that may have otherwise been hidden from prospective employers.}

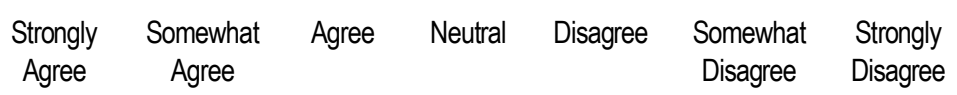

Section B: (Answer only if you recently received a promotion, pay raise, or enhanced job status.)

\begin{tabular}{|c|c|c|c|c|c|}
\hline $\begin{array}{l}\text { Strongly } \\
\text { Agree }\end{array}$ & $\begin{array}{l}\text { Somewhat } \\
\text { Agree }\end{array}$ & Agree & Neutral & Disagree & $\begin{array}{l}\text { Somewhat } \\
\text { Disagree }\end{array}$ \\
\hline
\end{tabular}

4. My employer was familiar with digital badges.

5. My employer asked about the digital badges on my resume.

6. My employer recognized the value of digital badges for employment decisions (ex.: hiring, promotion, pay raise, or enhanced job status).

\section{Section C: (Answer only if you recently received applied/interviewed for a new job.)}

\begin{tabular}{|c|c|c|c|c|c|}
\hline $\begin{array}{c}\text { Strongly } \\
\text { Agree }\end{array}$ & $\begin{array}{l}\text { Somewhat } \\
\text { Agree }\end{array}$ & Agre & Neutral & Disagree & $\begin{array}{l}\text { Somewhat } \\
\text { Disagree }\end{array}$ \\
\hline
\end{tabular}

7. The employer I interviewed with was familiar with digital badges.

8. The employer I interviewed with asked about the digital badges on my resume.

9. The employer I interviewed with recognized the value of digital badges for employment decisions.

\section{OPEN ENDED QUESTIONS (Everyone Answer)}

1. Looking back, do you perceive a value in earning digital badges through your Educational Technology coursework? Why or why not?

2. Would you continue to earn digital badges through other learning opportunities?

\section{SUMMARY}

The momentum gained by digital badges in the last several years in corporate training and higher education sparked an interest in the Educational Technology faculty at The University of Texas Rio Grande Valley. "As the digital age ushers in new possibilities for where and how people learn, digital badges are transforming how we document 
achievement" [9]. Similarly, former President Bill Clinton [9] who founded the Clinton Global Initiative, observed:

For a person to remain competitive in today's workforce, there must be continual learning. But traditional assessment tools are narrow in scope and often aren't able to communicate everything a person knows or has achieved. In order to capture the many and often informal ways that students and workers acquire knowledge and skills, and to enable institutions to recognize their accomplishments, we must embrace a more modern and comprehensive credentialing system (para. 1).

For months leading up to the EdTech Digital Badge Project, the Educational Technology faculty researched and discussed the benefits digital badges could offer their undergraduate online specialization students and graduates. Data collection for Phase I of this study has already started. Phase II, the implementation of the badges will take place over the Fall 2015 and Spring 2016 semesters, and it is expected that Phase III will be concluded in Fall 2016. This three-phase research study can serve as a template for university faculty to implement digital badge initiatives in their programs for enhancing students' motivation and academic achievement and provide learners with a way to document and promote their credentials.

\section{REFERENCES}

1. Achievery. (n.d.). Retrieved from http://achievery.com

2. Carey, K. (2012, November 02). Show me your badge. The New York Times, Education Life. Retrieved from http://www.nytimes.com/2012/11/04/education/edlife/show-me-your-badge.html?pagewanted=all\&_r=0

3. Dictionary.com. (2015). Definition of badge. Retrieved from: http://dictionary.reference.com/browse/badge

4. Global Kids Online Leadership Program. (2012, April 2). Badges for learning: An abridged recent history. Retrieved from http://www.olpglobalkids.org/content/badges-learning-abridged-recent-history

5. Joseph, B. (2012, April 2). Badges for learning: An abridged recent history. Global Kids Online Leadership Program. Retrieved from http://www.olpglobalkids.org/content/badges-learning-abridged-recent-history

6. Mozilla Open Badges Wiki. (2014). Badges. Retrieved from https://wiki.mozilla.org/Badges

7. Peer 2 Peer University \& Mozilla Foundation (2011). An open badge system framework: A foundational piece on assessment and badges for open, informal and social learning environments. Retrieved from: http://dmlcentral.net/resources/4440

8. ReconnectLearning. (n.d.). Chicago summer of learning. Retrieved from http://downloads.sproutfund.org/badges/CSOL.pdf

9. ReconnectLearning. (2014). Badges for learning. Retrieved from http://www.reconnectlearning.org/about

10. Wikipedia. (n.d.). Achievement. Retrieved from http://en.wikipedia.org/wiki/Achievement_(video_gaming) 